\title{
INFLUENCE OF BROMAZEPAM ON CORTICAL INTERHEMISPHERIC COHERENCE
}

\author{
Isabel Sampaio', Fernanda Puga', Heloisa Veiga², \\ Maurício Cagy ${ }^{3}$, Roberto Piedade 4 , Pedro Ribeiro ${ }^{5}$
}

\begin{abstract}
Benzodiazepines are among the most commonly prescribed medications due to their therapeutic efficacy in reducing anxiety and inducing sleep. Consequently, they have been widely employed in the pharmacological treatment of several disorders. Nevertheless, few studies have analyzed the effects of bromazepam in electroencephalographic activity (EEG). The present study aimed at investigating the modulatory effects of this drug on brain dynamics. Specifically, the effects of bromazepam (3mg) on EEG coherence were tested in a double-blind experiment. The sample, consisting of 10 healthy subjects ( 5 male and 5 female), was submitted to ten minutes of EEG recording. The electrophysiological measure (coherence) was analyzed across three experimental conditions: bromazepam, placebo 1, and placebo 2 . Results indicate that bromazepam significantly increases cortical interhemispheric coherence.
\end{abstract}

KEY WORDS: bromazepam, qEEG.

\begin{abstract}
Influência do bromazepam na coerência cortical inter-hemisférica
RESUMO - Benzodiazepínicos estão entre as medicações mais comumente prescritas devido à sua eficácia terapêutica para reduzir ansiedade e induzir sono. Conseqüentemente, eles têm sido amplamente empregados no tratamento de diversas desordens. No entanto, poucos estudos têm analisado os efeitos do bromazepam na atividade eletrencefalográfica (EEG). Assim, o presente estudo teve por objetivo investigar os efeitos modulatórios desta droga na dinâmica cerebral. Especificamente, os efeitos de $3 \mathrm{mg}$ de bromazepam na coerência eletrocortical foram analisados em um experimento duplo-cego. A amostra consistiu de 10 sujeitos sadios (5 homens e 5 mulheres), submetidos a dez minutos de captação do sinal de EEG. A medida eletrofisiológica (coerência) foi analisada em três condições experimentais: bromazepam, placebo 1 e placebo 2 . Os resultados sugerem que o bromazepam aumenta significativamente a coerência cortical inter-hemisférica.
\end{abstract}

PALAVRAS-CHAVE: bromazepam, EEGq.

It is acknowledged that the waking electroencephalographic activity (EEG) comprises direct relations to chemical changes in the brain induced by drugs. In other words, electroenchephalography is responsive to the unique characteristics of psychoactive substances ${ }^{1}$. In this context, the EEG has been widely employed in the assessment of electrophysiological changes induced by distinct medications. Its sensibility in detecting alterations produced by a specific substance may be enhanced by methods of quantitative analyses (qEEG) 2,3. Quantitative electroencephalography has become, throughout the years, a tool of great clinical utility in evaluating the effects of medications, predicting medication response, and in assessment of cognitive changes produced by such psychoactive substances. Once drugs have specific effects on wave morphology, changes in qEEG variables can be used to investigate mechanisms of drug action as well as to monitor and possibly predict efficacy.

However, very few studies analyzed the effects of benzodiazepines on qEEG variables. Saletu et al. ${ }^{4}$ compared the effects of a benzodiazepine agonist and diazepam (10 mg) and observed a "typical anxiolytic EEG profile", which is characterized by an increase in beta and a decrease in alpha. In another study, Link et al. ${ }^{5}$ analyzed the effects of granisetron

\footnotetext{
${ }^{1}$ Mestranda, Laboratório de Mapeamento Cerebral e Integração Sensório-Motora, Instituto de Psiquiatria (IPUB), Universidade Federal do Rio de Janeiro, Rio de Janeiro RJ, Brasil (UFRJ); ${ }^{2}$ Mestre em Saúde Mental, Laboratório de Mapeamento Cerebral e Integração Sensório-Motora, Instituto de Psiquiatria (IPUB), UFRJ; ${ }^{3}$ D.Sc. em Engenharia Biomédica, COPPE, UFRJ; ${ }^{4}$ Professor Adjunto III Doutor, Coordenador do Laboratório de Mapeamento Cerebral e Integração Sensório-Motora, IPUB / UFRJ; ${ }^{5}$ Professor Adjunto II PhD, Escola de Educação Física e Desportos (EEFD), Laboratório de Mapeamento Cerebral e Integração Sensório-Motora, IPUB / UFRJ; Professor Pesquisador, Universidade Castelo Branco (PROCIMH-UCB).
}

Received 13 April 2006, received in final form 17 July 2006. Accepted 20 September 2006.

Dra. Isabel Sampaio - Instituto de Psiquiatria (IPUB), Laboratório de Mapeamento Cerebral e Integração Sensório-Motora UFRJ Avenida Venceslau Brás 71 / Fundos - 22290-140 Rio de Janeiro RJ - Brasil. E-mail: belsampaio@gmail.com 
and lorazepam, and the exact same pattern of results, i.e., EEG profile, was observed. Specifically, studies employing bromazepam, possibly the most commonly prescribed benzodiazepine, are practically inexistent in the current literature. One of the few studies that examined the effects of this particular drug on qEEG was conducted by Fink et al. ${ }^{6}$. The effects of oral doses of bromazepam (9 $\mathrm{mg}$ ) and diazepam (10 mg) in EEG data were analyzed and an analogous result was reached: increased beta and decreased alpha activity. Such changes seem to be characteristic for benzodiazepines.

The previously cited studies that employed qEEG, in addition to being long-standing, only analyzed power distribution. References in the current literature of studies focusing on changes related to bromazepam intake in other qEEG variables are even scarcer. Coherence measures, for example, can be used to assess functional relationships between cortical areas $^{7}$. Coherence is a measure of synchronization between two areas. Hence, coherence analyses have provided the means to assess functional connectivity between cortical regions. The use of coherence analyses have gradually increased in the last two decades. Several researchers regard this measure as having considerable clinical value once it can directly reflect neural network connectivity and dynamics $^{8-11}$. Decreased coherence, for instance, is observed in major depression associated with organic brain disorders ${ }^{12}$, in patients with seasonal affective disorder $^{13}$, in male depression ${ }^{14}$, and in childhood and adolescent depression ${ }^{15}$. In addition, decreases in interhemispheric coherence are observed in Alzheimer patients and seem to be related to other age-related decreases ${ }^{16,17}$. Furthermore, coherence analyses have been used to characterize regional changes in neuronal couplings and information transfer related to semantic aspects of object recognition in humans ${ }^{18}$, anticipation of somatosensory and visuomotor events ${ }^{19}$, and central executive functions of working memory ${ }^{20}$, among others. However, none of these studies have analyzed the effects of a specific drug on interhemispheric connectivity (i.e., coherence).

In this context, the present study aimed at investigating the effects of bromazepam on the coupling of cortical areas (coherence) and the strength of interhemispheric connectivity.

\section{METHOD}

Subjects - The sample consisted of 10 volunteers, 5 male and 5 female, with ages varying between 21 and 38 years ( $27 \pm 5$ years). All subjects were healthy, free of cognitive deficits and were not making use medication or any psy- choactive or psychotropic substance at the time of the test. To assure that subjects did not present any impairment of their physical and mental health, and to identify and exclude from the experiment any subjects who could contaminate future results, a questionnaire was applied. Subjects signed a consent form, where the experimental condition was thoroughly described. The experiment was submitted to the Psychiatric Institute's ethics committee for approval.

Study design and procedures - Subjects received a capsule (bromazepam or glucose) on three different occasions under a randomized, double-blind, crossover study. The procedures consisted of a three-day treatment: a day of bromazepam (B) and two of placebo (P1 and P2). The procedures were standardized in the following routine: 1) 10 minutes of EEG recording (5' eyes-closed / 5' eyes-open); 2 ) Administration of capsule (bromazepam or placebo); 3) The second EEG $\left(10^{\prime}\right), 20$ minutes after drug ingestion; 4) The third EEG $\left(10^{\prime}\right), 60$ minutes after drug ingestion.

EEG acquisition - The study design respected the International Pharmaco-EEG group guidelines. International 10/ 20 System $^{21}$ for electrode placement (referred to linked earlobes) was used with a 20-channel Braintech-3000 (EMSAMedical Instruments, Brazil). The 20 monopolar electrodes were arranged in a nylon cap (ElectroCap Inc., Fairfax, VA, USA). Impedance for EEG and EOG electrodes were under $5 \mathrm{~K} \Omega$ and $20 \mathrm{~K} \Omega$, respectively. Visual inspection was employed for detection and elimination of artifacts. The data acquired had total amplitude of less than $100 \mu \mathrm{V}$. The signal was amplified with a gain of 22,000. Eye-movement (EOG) artifact was monitored with a bipolar electrode montage using two 9-mm diameter electrodes attached above and on the external canthus of the right eye. Moreover, Independent Component Analysis (ICA) was applied to remove possible sources of artifacts. The EEG signal was analogically filtered between $0.16 \mathrm{~Hz}$ (high-pass) and 35 $\mathrm{Hz}$ (low-pass), and sampled at $200 \mathrm{~Hz}$. The acquisition software, developed at the Brain Mapping and Sensorimotor Integration Lab, was employed with the following digital filters: Notch $(60 \mathrm{~Hz})$, high-pass of $0.3 \mathrm{~Hz}$ and low-pass of $25 \mathrm{~Hz}$.

Data processing and analysis - At least 2 min of artifact-free data were extracted from the EEG record for quantitative analysis. A Matlab 5.3 ${ }^{\circledR}$ (Mathworks Inc., Naticj, MA, USA) routine was implemented to perform a spectral analysis and estimate the specific parameter of interest: bandlimited EEG coherence, for delta (1.0-3.5 Hz), theta (4.0-7.5 $\mathrm{Hz})$, alpha $(8.0-12.0 \mathrm{~Hz})$, and beta $(13-25 \mathrm{~Hz})$ frequency bands, and between all pair combinations of electrodes. Coherence reflects the joint variation in electrical activity between homologous electrode pairs (i.e., electrodes in the same position on opposite sides of the head). In other words, coherence is an estimate of shared variance.

Spatial localization - Electrodes located over frontal, central and parietal areas were selected. Specifically, frontal areas were analyzed due to their association with attentional mechanisms, motivation and planning. Central and pari- 
etal electrodes were analyzed since they are representative of premotor and primary motor areas, as well as primary somatosensory and higher order somatosensory areas ${ }^{22}$.

Statistical analysis - Three-Way Anova, condition x moment $x$ electrode $(3 \times 3 \times 3)$, was performed for the electrophysiological measure, i.e., coherence, in each frequency band separately $(p \leq 0.05)$. A Post Hoc (Scheffé) was applied a posteriori. Experimental conditions were established as bromazepam (B), placebo 1 (P1) and placebo 2 (P2) and experimental moments as $0^{\prime}$ (before drug administration), $20^{\prime}$ (twenty minutes after drug administration), and 60' (sixty minutes after drug administration). The selected electrode the pairs were F3-F4, C3-C4, and P3-P4.

\section{RESULTS}

Figure illustrates coherence variations across conditions (B, P1, P2), moments $\left(0^{\prime}, 20^{\prime}, 60^{\prime}\right)$ and electrodes (F3-F4, C3-C4 and P3-P4) in the delta, theta, alpha, and beta frequency bands.

In delta (1-A), the three-way Anova revealed significant main effects of condition $\left[F_{(2,267)}=6.446 ; p=\right.$ $0.002]$ and electrode site $\left[F_{(2,267)}=6.854 ; p=0.001\right]$. No interactions were observed. The Post Hoc pointed out to the following differences: $B$ and P1 $(p=0.004)$,
$B$ and P2 (p=0.024); F3-F4 and C3-C4 $(p=0.016)$, C3C4 and P3-P4 ( $p=0.003)$.

In theta (1-B), the analysis revealed significant main effects of condition $\left[F_{(2,267)}=7.170 ; p=0.001\right]$, moment $\left[F_{(2,267)}=3.968 ; p=0.020\right]$, and electrode site $\left[F_{(2,267)}=21.049 ; p=0.000\right]$. No interactions were observed. The Post Hoc pointed out to the following differences: $B$ and P1 ( $p=0.001), P 1$ and P2 $(p=0.038)$; $0^{\prime}$ and 60' $(p=0.020) ; F 3-F 4$ and P3-P4 $(p=0.000)$, C3C4 and P3-P4 ( $p=0.000)$.

In alpha $(1-C)$, main effects of condition $\left[F_{(2,267)}=\right.$ 7.537; $p=0.001]$, moment $\left[F_{(2,267)}=4.825 ; p=0.009\right]$, and electrode site $\left[F_{(2,267)}=21.345 ; p=0.000\right]$ were found. No interactions were observed. The Post Hoc pointed out to the following differences: $B$ and $P 1$ $(p=0.011), P 1$ and $P 2(p=0.002) ; 0^{\prime}$ and 60' $(p=0.009) ;$ F3-F4 and C3-C4 ( $p=0.000)$, F3-F4 and P3-P4 ( $p=0.000)$.

In beta (1-D), the three-way Anova revealed main effects of condition $\left[F_{(2,267)}=13.028 ; p=0.000\right]$, moment $\left[F_{(2,267)}=6.372 ; p=0.002\right]$, and electrode site $\left[F_{(2,267)}=\right.$ 36.687; $p=0.000]$. No interactions were observed. The Post Hoc pointed out to the following differences: $B$ and P1 $(p=0.000), P 1$ and P2 $(p=0.001) ; 0^{\prime}$ and 60' $(p=$ 0.002); F3-F4 and C3-C4 ( $p=0.000), F 3-F 4$ and P3-P4 $(p=0.000), C 3-C 4$ and P3-P4 $(p=0.000)$.
A)

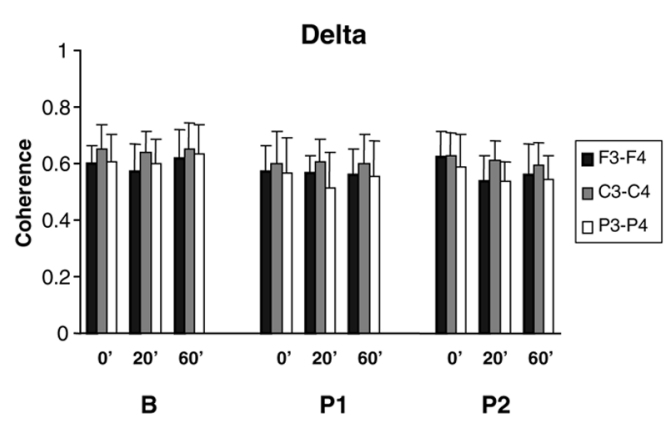

C)

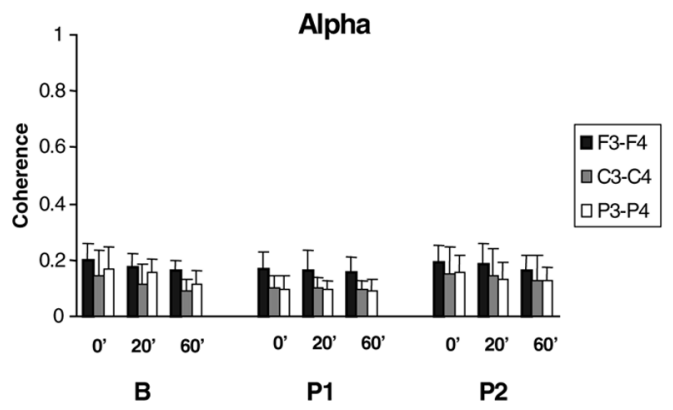

B)

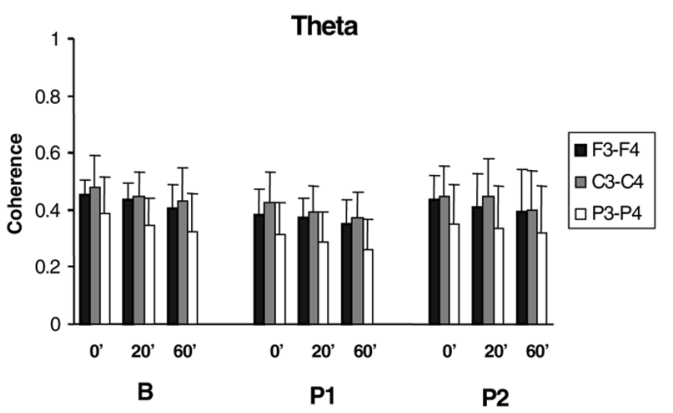

D)

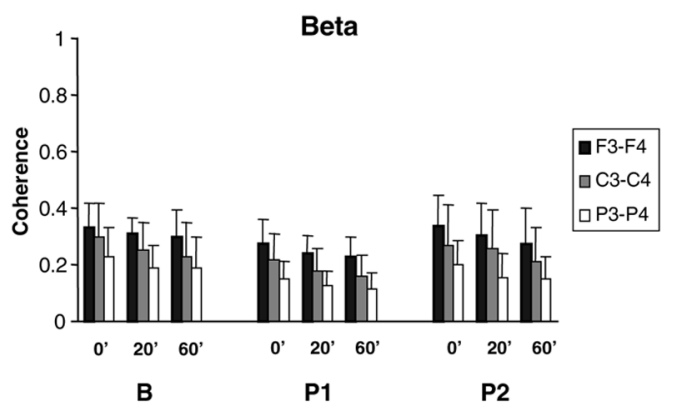

Figure. EEG coherence variation across conditions $(B, P 1, P 2)$, moments $\left(0^{\prime}, 20^{\prime}, 60^{\prime}\right)$, and electrodes (F3-F4, C3-C4, and $P 3-P 4)$, in delta $(A)$, theta $(B)$, alpha (C), and beta $(D)$. 


\section{DISCUSSION}

The present study aimed at investigating the specific effects of bromazepam on the coupling of cortical areas and the strength of interhemispheric connectivity, as expressed in terms of coherence values. Like all benzodiazepines, bromazepam facilitates the release of GABA, the major inhibitory neurotransmitter. Such facilitation results in inhibition of brain cognitive functions ${ }^{23}$. Thus, by using bromazepam, one can observe the consequences of inhibition on the connectivity between different cortical areas. The present study investigated whether an inhibitory system would indeed be responsible for functional decoupling between cortical areas, assuming that inhibition would weaken or even impair cortical functional connections. In other words, we expected to observe a decoupling between areas (i.e, lower coherence values) after bromazepam intake. However, the results indicated otherwise.

Specifically, coherence values increased in the bromazepam condition when compared to both placebo groups in all frequency bands. It must also be stressed that a marked difference was observed between the slow bands (delta and theta) and the fast bands (alpha and beta): coherence values were significantly higher in the slower frequencies ranges. Significant differences were also observed across moments, except in the delta band. In synthesis, the drug clearly promoted an enhancement of cortical interhemispheric coherence, which is in accordance with Fingelkurts et al. ${ }^{24}$, who conducted possibly the most expressive work related to the effects of a benzodiazepine on interhemispheric coherence. These authors investigated whether lorazepam would generate a functional decoupling of cortical areas and concluded that, unexpectedly, the drug yielded a widespread increase in the inter-area functional connectivity. In this sense, the results of the present study indicate that the cortical inhibition produced by this benzodiazepine may be an efficient mechanism. As stated by Fingelkurts et al. ${ }^{24}$, despite the common belief that this pharmacological class impairs brain functioning by switching off irrelevant functional connections, it seems that benzodiazepine intake increases the strength of functional links and promotes functional coupling between different cortical areas.

These results are not so atypical. Other studies, employing coherence analysis on different experimental models, have reached similar outcomes. For instance, it has been shown that states of minimal cognitive processing often exhibit widespread spatially coherent $\mathrm{EEG}^{25}$. In the same way, an increase of coherence values has been observed during non-REM sleep and drowsiness ${ }^{26}$, during sub-anesthetic concentrations ${ }^{27}$, and during meditation, which was accompanied by an anxiety decrease ${ }^{28}$. A possible explanation for such pattern of results is that GABA seems to have an excitatory action on several brain systems $^{29}$. In this sense, GABA is not a single-action neurotransmitter ${ }^{30}$. Therefore, the enhancement in interhemispheric connectivity, expressed by an increase in coherence values, after bromazepam intake, may be the result of GABA excitatory actions.

Nevertheless, further studies, using different doses of bromazepam, are necessary to truly understand the effects of this benzodiazepine not only on brain dynamics, but on coherence and other qEEG variables. Additional studies are also necessary to thoroughly understand how different medications affect cortical synchronicity and the strength of interhemispheric connectivity.

\section{REFERENCES}

1. Saletu B, Anderer P, Saletu-Zyhlarz GM. EEG topography and tomography (LORETA) in the classification and evaluation of the pharmacodynamics of psychotropic drugs. Clin EEG Neurosci 2006;37:66-80.

2. Anghinah R, Kanda PAM, Jorge MS, Lima EE, Pascuzzi I, Melo AC. Estudo da coerência do eletrencefalograma para a banda de freqüência alfa em indivíduos adultos normais e com provável demência do tipo Alzheimer. Arq Neuropsiquiatr 2000;58:272-275.

3. Veiga H, Deslandes A, Cagy M, Fiszman A, Piedade RA, Ribeiro P. Neurocortical electrical activity tomography in chronic schizophrenics. Arq Neuropsiquiatr 2003;61:712-717.

4. Saletu B, Grünberger J, Linzmayer L. On the central effects of a new partial benzodiazepine agonist RO 16-6028 in man: pharmaco-EEG and psychometric studies. Int J Clin Pharmacol Ther Toxicol 1989;27:51-65.

5. Link CS, Leigh TJ, Fell GL. Effects of granisetron and lorazepam, alone and in combination, on the EEG of human volunteers. Br J Clin Pharmacol 1991;31:93-97.

6. Fink M, Irwin P, Weinfeld RE, Schwartz MA, Conney AH. Blood levels and encephalographic effects of diazepam and bromazepam. Clin Pharmacol Ther 1976;20:184-191.

7. Besthorn C, Förstl H, Geiger-Kabisch C, Sattel H, Gasser T. EEG coherence in Alzheimer disease. Electroenceph Clin Neurophysiol 1994; 90:242-245

8. Harmony T, Marosi E, Fernandez T, Bernal J, Rodriguez M, Reyes A. EEG coherences in patients with brain lesions. Int J Neurosci 1994;74: 203-226.

9. Tatcher RW. Normative EEG databases and EEG biofeedback. J Neurother 1998;2:8-39.

10. Lubar JF, White JN, Swartwood MO, Swartwood JN. Methylphenidate effects on global and complex measures of EEG. Pediatr Neurol 1999; 21:633-637.

11. Pilgreen KL. Physiologic, medical, and cognitive correlates of electroencephalography. In: Nunez PL (Ed). Neocortical dynamics and human EEG rhythms. New York: Oxford University Press, 1995:195-248.

12. Brassen S, Braus DF, Weber-Fahr W, Tost H, Moritz S, Adler G. Lateonset depression with mild cognitive deficits: electrophysiological evidences for a preclinical dementia syndrome. Dement Geriatr Cogn Disord 2004;18:271-277.

13. Passynkova NR, Volf NV. Seasonal affective disorder: spatial organization of EEG power and coherence in the depressive state and in lightinduced and summer remission. Psychiatry Res 2001;108:169-185.

14. Knott V, Mahoney C, Kennedy S, Evans K. EEG power, frequency, asymmetry and coherence in male depression. Psychiatry Res 2001;106: 123-140. 
15. Armitage R, Hoffmann R, Emslie G, Rintelmann J, Robert J. Sleep microarchitecture in childhood and adolescent depression: temporal coherence. Clin EEG Neurosci 2006;37:1-9.

16. Wada Y, Nanbu Y, Koshino Y, Yamagushi N, Hashimoto T. Reduced interhemispheric EEG coherence in Alzheime disease: analysis during rest and photic stimulation. Alzheimer Dis Assoc Disord 1998;12:175-181.

17. Duff FH, McAnulty GB, Albert MS. Effects of age upon intrehemispheric EEG coherence in normal adults. Neurobiol Aging 1996;17:587-599.

18. Supp GG, Schlogl A, Fiebach CJ, et al. Semantic memory retrieval: cortical couplings in object recognition in the N400 window. Eur J Neurosci 2005;21:1139-1143.

19. Babiloni C, Brancucci A, Vecchio F, Arendt-Nielsen L, Chen AC, Rossini PM. Anticipation of somatosensory and motor events increases centro-parietal functional coupling: an EEG coherence study. Clin Neurophysiol 2006.

20. Sauseng P, Klimesch W, Schabus M, Doppelmayr M. Fronto-parietal EEG coherence in theta and upper alpha reflect central executive functions of working memory. Int J Psychophysiol 2005;57:97-103.

21. Jasper H. The ten-twenty electrode system of the international federation. Electroencephalogr Clin Neurophysiol 1958;10:371-375.

22. Kandel E, Schwartz S, Jessel T. Principles of neuroscience, 4.Ed. New York: McGraw-Hill, 2000.
23. Katzung BG. Basic Clinical Pharmacology, 6.Ed. London: Pretence-Hall International, 1995

24. Fingelkurts AA, Kivisaari R, Pekkonen E, Ilmoniemi RJ, Kahkonen S. Enhancement of GABA-related signalling is associated with increase of functional connectivity in human cortex. Hum Brain Mapp 2004;22:27-39.

25. Nunez PL. Toward a quantitative description of large-scale neocortical dynamic function and EEG. Behav Brain Sci 2000;23:371-437.

26. Bullock TH, McClune MC, Achimowicz JZ, Iragui-Madoz VG, Duckrow $\mathrm{RB}$, Spencer SS. EEG coherence has structure in the millimeter domain: subdural and hippocampal recordings from epileptic patients. Electroencephalogr Clin Neurophysiol 1995;95:161-177.

27. Nunez PL. Neocortical dynamics and human EEG rhythms. New York: Oxford University Press, 1995.

28. Aftanas LI, Golocheikine SA. Human anterior and frontal midline theta and lower alpha reflect emotionally positive state and internalized attention: high-resolution EEG investigation of meditation. Neurosci Lett 2001;310:57-60.

29. Gulledge AT, Stuart GJ. Excitatory actions of GABA in the cortex. Neuron 2003;37:299-309.

30. Köhling R. GABA becomes exciting. Science 2002;298:1350-1351. 